\title{
"Are You a Computer?" Opening Exchanges in Virtual Reference Shape the Potential for Teaching
}

\section{Paula R. Dempsey}

\begin{abstract}
Academic reference librarians frequently work with students who are not aware of their professional roles. In online interactions, a student might not even realize that the librarian is a person. The ways students initiate conversations reveal their understanding of the mutual roles involved in reference encounters. Conversation analysis of live chat transcripts at two institutions establishes the importance of opening exchanges to shape the potential for teaching. Chats that students open with relational cues (greeting, introduction, courtesy, verbal softeners) last longer than chats without these cues. Longer chats include more expressions of enthusiastic gratitude. The transcripts show evidence of successful strategies by librarians to shift chats from transactional openings to conversations with potential for engaged learning.
\end{abstract}

An early stage of analysis was presented as a poster at the Library Assessment Conference 2014, Seattle, Washington.

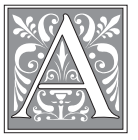

question flashes onto a screen with a demanding chirp. Anonymous. Lacking context. Polite and friendly or abrupt and mechanical. Then another, and another. Librarians providing live chat reference service must respond instantly in a way that fosters professional standards. Yet no research has investigated how opening exchanges between students and librarians in chat reference affect the potential for teaching and learning. Analysis of how students open chat reference interactions and how librarians respond is useful for improving chat reference and promoting the educational role called for in the Association of College \& Research Libraries (ACRL) Standards for Libraries in Higher Education, especially Performance Indicator 3.4: "Library personnel provide regular instruction in a variety of contexts and employ multiple learning platforms and pedagogies."1

The purpose of this study was to apply conversation analysis (CA) theory and techniques to one week's live chat reference transcripts at two libraries. Graduate training in CA as part of doctoral work in sociology fed my interest in and skill set for this approach. ${ }^{2}$ Research questions were as follows:

- In what ways do students begin chat reference interactions?

- To what extent do student openings vary at different institutions?

Paula R. Dempsey is Assistant Professor and Research Services E Resources Librarian in the Richard J. Daley Library at the University of Illinois at Chicago; e-mail: dempseyp@uic.edu. (C) 2016 Paula R. Dempsey, Attribution-NonCommercial-ShareAlike 4.0 (http://creativecommons.org/licenses/by-nc-sa/4.0/) CC BY-NC-SA. 
- How do students' choices about beginning chats influence the length of the interaction and their satisfaction?

- What first response strategies do librarians use to prompt students to interact with them as teachers?

\section{Review of the Literature}

Two streams of research inform this study. One stream is work in librarianship that investigates the teacher identity among academic reference librarians, as well as whether and how teaching can be effective in virtual interactions. The other is work in sociolinguistics, specifically CA, and its potential benefits for empirical study of these issues. The present study fills gaps in both literatures. It provides empirical evidence of everyday identity work among librarians at two universities. It adds to the existing literature by providing the first interpretive analysis of how opening exchanges in chats affect their duration and student satisfaction and can set the stage for teaching. In sociolinguistics, the study contributes evidence from librarianship that supports and extends CA theory.

Researchers in librarianship have contested whether librarians are or should be teachers. In a classic article, Pauline Wilson refuted the teacher identity as an artifact of inflated professional status. ${ }^{3}$ Constance Miller and James Rettig also took the position that librarians should not teach patrons to be independent. Delivery of information was to be a bulwark against obsolescence. ${ }^{4}$ However, as noted previously, those who advocate an educational role have prevailed in national professional standards. James K. Elmborg made a case for teaching as the core of academic reference work and encouraged librarians to use questions to engage students in learning. ${ }^{5}$ Scott Walter used qualitative interviews to understand how academic librarians framed teaching as central to their role, even as they struggled with the stress of multiple demands. ${ }^{6}$

Studies of virtual reference (VR, which includes e-mail and SMS/text interactions as well as chat) also land on the educational side of the debate. Miriam L. Matteson, Jennifer Salamon, and Lindy Brewster synthesized research from 1995 to 2010 on chat reference service and concluded "that instruction can be provided (and evaluated) in chat service, that many chat interactions include instructional elements, and that users do ask for instruction."7 Christina M. Desai and Stephanie J. Graves analyzed teaching methods in VR interactions and concluded that "Research should not be a magic act performed by the librarian" 8 and that "librarians should not rely strictly on patron questions to determine whether or not to practice instruction." ${ }^{9}$ Susan Avery and David Ward developed teaching goals for VR. ${ }^{10}$ Marie L. Radford et al. found that "The academic librarian thus generally assumes a teaching role or line in reference encounters with students." ${ }^{11}$ And Terrence W. Epperson and Alan Zemel noted the "institutional imperatives" of both fully understanding the underlying research need and offering instructions and information that transcend the patron's initial question. ${ }^{12}$

Commitment to teaching and learning can benefit from attention to CA, which has helped a range of professions understand and improve communication with clients. Studies of opening exchanges between clients and librarians, ${ }_{1}^{13}$ physicians, ${ }^{14}$ police and 911 emergency call takers, ${ }^{15}$ and telephone counselors ${ }^{16}$ all demonstrate the importance of establishing recognition early in the interaction about the identity of the professional and the philosophy of the service. Across professions, researchers have found that CA can improve service by correcting, exemplifying, and expanding the normative models, theories, and quasi-theories about interactions with clients. ${ }^{17}$ John M. Budd's discussion of discourse analysis, including CA, supports this view, specifically for improving effectiveness in online reference service. ${ }^{18}$ 
CA considers everyday talk as the basis for creating and maintaining the social world..$^{19}$ Deborah Schiffrin explained one theoretical basis of CA, ethnomethodology, which "seeks to discover the methods by which members (of a society) produce a sense of social order." ${ }^{20}$ Applied to VR, for example, CA is useful to discover how students and librarians collaborate to make meaning about the research process. CA examines bodies of naturally occurring utterances, including errors, hesitations, and silences, all of which may be important signals of social dynamics. ${ }^{21} \mathrm{CA}$ is appropriate for any dialogue in which the participants freely control the order of their turn taking (unlike debates or interviews with formally ordered turns). ${ }^{22}$ Chat transcripts record these momentto-moment details, but CA researchers must account for differences between written and oral utterances. ${ }^{23} \mathrm{CA}$ is an inductive process. According to Epperson and Zemel, researchers should avoid imposing "analytic categories and classifactory schemes that obscure the extremely situated and collaborative nature of reference work." 24

Epperson and Zemmel provide an excellent overview of the underlying theories of CA..$^{25}$ For this study, it is sufficient to focus on how CA deals with two structural features of talk: preferred/dispreferred responses and the work of recognition in opening exchanges. In CA, a "preferred response" is not specific to a participant's internal state, but rather a functional aspect of conversational structure. Preferred responses are briefer. They allow conversation to continue smoothly without a pause or an unexpected turn: a question is answered, a command is complied with, a statement is acknowledged, an offer is accepted..$^{26}$ A dispreferred response takes longer because the second speaker must explain or justify an unexpected response. ${ }^{27}$ Note that a recipient might welcome a response that is dispreferred in terms of conversational structure. For example, a librarian might respond more generously than a student had hoped for. Another key point is that CA does not claim to predict what response is preferred, only to be able to recognize a dispreferred response based on its effect on the flow of talk.

CA has established that recognition is a structural requirement for opening a state of talk. Don H. Zimmerman found that the first turns in telephone conversations "are regularly devoted to establishing a mutually oriented-to set of identities implicative for the shape of what is to follow." ${ }^{28}$ Emanuel A. Schegloff saw the identity, purposes, and relationships of the parties to the talk as both shaping and shaped by the interaction. The opening moves establish roles for both parties, and further moves are constrained by the relationship between the participants "as it develops from moment to moment." 29 Greetings are essential for achieving recognition. ${ }^{30}$ Harvey Sacks argues that, in faceto-face encounters, omitting a greeting before asking a question is a strategy for not starting a conversation. Omitting a greeting establishes roles as transactional rather than relational. ${ }^{31}$ In addition to greetings, other ritual exchanges or relational cues serve both to save face for participants and to order communication, such as introducing oneself, using courtesy tokens (please, thank you), and minimizing requests with verbal "softeners" ("quick question," "just wondering"). ${ }^{32}$

Openings that lack relational cues might strike the recipient as abrupt, or even rude. CA suggests another way to understand them. In the right circumstances-with a stranger whom we do not expect to see again - asking a question without greeting the person is not rude. It is a way to indicate that we will not burden the person with an undesired conversation. CA theory suggests that librarians who intend to teach in VR must learn how to shift the interaction from transactional into conversational mode. This study provides evidence of everyday strategies librarians use to accomplish this shift.

\section{Data and Methods}

This study analyzed 412 transcripts of live chat interactions between librarians and students at University Library 1 (UL1) and University Library 2 (UL2) generated in 
a single week of the academic term in fall 2013 (UL1 $n=242$, UL2 $n=170$ ). Both institutions used the LibraryH3lp instant messaging platform. Neither provided reference via SMS/text messaging for the period studied..$^{33}$ University 1 is private, doctoral level, and larger than University 2, which is public and master's level. Both universities are diverse, urban, multicampus institutions with a preponderance of commuter students (90\% at University 1 and $100 \%$ at University 2). The institutions invest roughly the same amount per student in library services according to data from the Integrated Postsecondary Education Data System (IPEDS) (see table 1).

\begin{tabular}{|l|l|c|c|c|c|}
\hline \multicolumn{6}{|c|}{ TABLE 1 } \\
\hline & Carnegie Class & $\begin{array}{c}\text { Total } \\
\text { FTE }\end{array}$ & Librarians & $\begin{array}{c}\text { Librarians } \\
\text { and Other } \\
\text { Professional Staff } \\
\text { per 1,000 FTE }\end{array}$ & $\begin{array}{c}\text { Total Library } \\
\text { Expenditures } \\
\text { per FTE }\end{array}$ \\
\hline UL1 & $\begin{array}{l}\text { Doctoral/Research } \\
\text { universities- } \\
\text { intensive }\end{array}$ & 21,494 & 42.6 & 1.98 & $\$ 500.14$ \\
\hline UL2 & $\begin{array}{l}\text { Master's Colleges } \\
\text { and universities I }\end{array}$ & 8,176 & 18.0 & 2.26 & $\$ 462.24$ \\
\hline
\end{tabular}

At both libraries, chat transactions comprised about one-quarter of total patron inquiries (walk-up, phone, e-mail, and live chat). Table 2 provides a rough typology of the chat interactions. At both libraries, more than half of the chats can be classified as reference questions, as defined by the American Library Association Reference and User Services Association (UL1 59\%, UL2 55\%). ${ }^{34}$ The largest category of reference question was how to find information on a subject or topic; the second largest was how to locate a known article, book, or film; the smallest was how to search for a specific material type (newspapers, films, or microfilm).

\begin{tabular}{|l|c|c|c|c|}
\hline \multicolumn{5}{|c|}{ TABLE 2 } \\
\hline & Directional/Policy & Reference \\
\hline & & Subject/Topic & Known Item & Material Type \\
\hline UL1 & $41 \%$ & $33 \%$ & $23 \%$ & $3 \%$ \\
\hline UL2 & $45 \%$ & $37 \%$ & $15 \%$ & $3 \%$ \\
\hline *Transcript totals include chats with nonstudents not analyzed in the rest of the study. \\
\hline
\end{tabular}

Staffing models varied for the two libraries at the time of the study. UL1 staffed walk-up reference desks with 8 full-time MLS librarians, 10 part-time MLS librarians, and 6 undergraduate assistants, all of whom monitored chat reference from private offices during the business day and from a public desk in the evenings until midnight and over the weekend. UL2 staffed reference in person and virtually with 13 MLS librarians, 2 paraprofessional staff, and 3 graduate student assistants. UL2 librarians monitored chat reference from public desks where information services were also offered in person and by telephone. The data do not identify the status of the "librarian" responding, and students are not aware whether they are chatting with a peer or a professional unless they ask. 
The purposive sampling method captures interactions with students when they are most likely to be working on research projects: after midterm exams and before finals week. At this point in the term, professors have clarified expectations and students still have time to conduct research. Later, when deadline pressure mounts, students may be desperate for direct service and less open to information literacy instruction. The sample is appropriate for the research questions because the goal is not to identify a representative set of questions, but rather to understand how librarians frame interactions when students are most likely to be doing substantive research and to be receptive to new concepts and skills.

The Institutional Review Board determined that, because the data are anonymous, the activity does not meet the definition of human subjects research. However, as Sarah J. Tracy notes, the researcher's obligation does not end with procedural ethics such as ensuring anonymity. ${ }^{35}$ In addition, relational ethics entail demonstrating respect for the work of these anonymous librarians and student assistants. ${ }^{36}$ The analysis keeps in mind the busy setting and competing demands of VR work. No single interaction, no matter how flawed, represents any individual's interpersonal skills, reference knowledge, or commitment to student learning.

After removing from the data all information identifying institutions and individuals, the first step in the analysis was to upload transcripts to NVivo software, which stores texts, provides sophisticated search tools, and allows the researcher to apply brief descriptive phrases known as "codes" to portions of text. All of the text in any transcript coded for a structural element or theme comprises a "node." Examples of structural elements are the first words typed by each student coded to the node "Opening bid" and the first words typed by each librarian coded to the node "Librarian first response." An example of a thematic node is one named "Awesome": a rough measure of student satisfaction coding expressions of enthusiastic gratitude such as "awesome!!", "sweeeeet!", "thank you!!!!!!!, or "yay." Using the search tools in NVivo, I gathered all examples of relevant terms in all 412 transcripts. In the next phase, "coding on," I re-examined the codes in each node to omit (or "uncode") irrelevant passages and create new codes as themes of interest emerged. Such rigorous, systematic, iterative coding is known as the constant comparative method. ${ }^{37}$

Two quantitative strategies informed the analysis. First, I calculated the duration of each transcript using time stamps for the first and last line of the chat, omitting gaps before responses to measure only active chat time. ${ }^{38}$ Second, I ran a basic word count for opening exchanges, which revealed a large difference in the rate of greetings at each library. This discovery led to further coding and creation of new nodes for other relational cues in opening exchanges, building on CA theory discussed in the literature review. Node names for relational cues follow:

- Identity: Whether and how parties introduced themselves

- Polite: Please, thank you, and other courtesies

- Softener: Expressions like "Just curious," "I was wondering," and "I have a quick question" that make requests sound less demanding or intrusive

I used these nodes to create two data sets: transcripts with conversational openings in which students entered the chat using relational cues, and transcripts with transactional openings, in which students omitted relational cues. Comparative analysis of duration and student gratitude in the two sets revealed large differences on both measures.

The next step was systematic interpretation of each transcript to learn how specific conversational moves led to the differences observed in duration and student satisfaction. This is not a classic inductive content analysis built by isolating recurring themes to build grounded theory. ${ }^{39}$ It is also not a directed content analysis applying previously defined categories to validate or extend existing theory. ${ }^{40}$ Rather, it takes 
the interpretive approach that Douglas Ezzy describes as "ongoing dialogue between preexisting understandings and the data, derived from participation in the world." ${ }^{41}$ At this stage, it was important to both account for and temporarily suspend my personal experience with VR. Ezzy asks researchers to recognize that credible analysis depends on not denying or hiding preconceptions, but explicitly stating them and continuously testing them against the data. ${ }^{42}$ In this study, the key preconception (supported by previous research) is that teaching is both possible and valuable in VR practice. Complete examples of transcripts allow readers to judge the validity of the interpretation and to bring their own experience to the texts. The interpretive approach does not preclude the possibility of alternative meanings but strives for internal consistency. ${ }^{43}$

\section{Findings}

Analysis of the 412 transcripts showed that students and librarians at the two libraries used relational cues at different rates, as shown in word clouds ranking the most frequent 50 words longer than 4 characters in opening exchanges (see figure 1). At UL1, 76 percent of students included a greeting in their opening bids, but only 48 percent of students at UL2 greeted the librarian. In response, 89 percent of UL1 librarians greeted the student, and only 24 percent of UL2 librarians did so.

On the left side of figure 1, note that the student opening bids display similar rates of relational cues (circled). The librarian first responses on the right display more relational cues for UL1. Also note the word "moment" in UL2 librarian first responses. UL2 librarians started chats with busy indicators (asking the patron to wait or apologizing after a delay) more often than they said hello. The overall rate of busy indicators

\begin{tabular}{|c|c|c|}
\hline \multicolumn{3}{|c|}{$\begin{array}{l}\text { FIGURE } 1 \\
\text { Most Frequent } 50 \text { Words Longer than } 4 \text { Characters in Opening Exchanges }\end{array}$} \\
\hline & Student Opening Bids & Librarian First Responses \\
\hline UL1 & $\begin{array}{l}\text { wondering } \\
\text { papelibrary } \\
\text { ticlehe } \\
\text { trying }\end{array}$ & 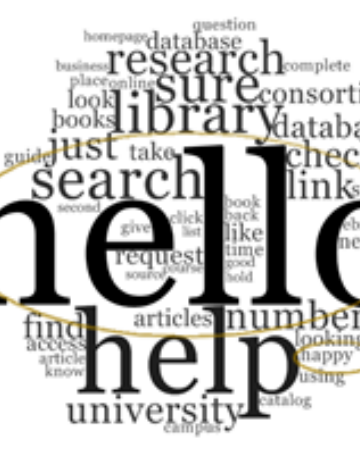 \\
\hline UL2 & question & 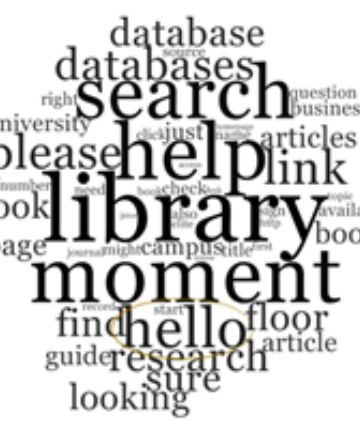 \\
\hline
\end{tabular}


throughout the chats (not only in opening exchanges) is similar (14\% of UL1 chats; $15 \%$ of UL2 chats), but more questions at UL2 go unanswered (3\% of UL1 chats; $14 \%$ of UL2 chats). One possible explanation for differences in rates of dropped chats is whether librarians monitor chat at a public service point.

The high rate of relational cues in UL1 opening exchanges correlates with average chat durations that are 95 percent longer than at UL2 (see figure 2). One likely reason for this difference is service norms at the two libraries. The Ask A Librarian page at UL2 restricts chat reference to brief, factual questions. UL1 states no such policy. The data demonstrate a stronger preference among librarians at UL1 for first responses that encourage conversation, leading to longer interactions. UL1 students might use more greetings because they have learned it is appropriate from previous experience with live chat. In the handful of return visits in these data sets, students who ask a follow-up question do include relational cues in the opening bid.

At both libraries, chats are longer when students open the chat with relational cues than when they omit these cues: 78 percent longer at UL1 and 82 percent longer at UL2. To understand why bids that open without relational cues are briefer on average, remember the theoretical claim that recognition is required to start a conversation, but that one can initiate a transaction without starting a conversation. This tactic is most common when participants do not know each other and their mutual roles are undefined. Although a study by Sharon Lauricella and Robin Kay supported the common assumption that students are familiar with chat technology, they also found that students use it informally to connect with friends and are unlikely to chat online with faculty. ${ }^{44}$ Students' preference for using chat with peers might be an additional factor in role ambiguity.

Three common types of transactional opening bid display uncertainty about the mutual roles involved in VR:

1. Summons: "Is anyone there?"

2. "Search engine" bids entered as if interacting with a computer: "How to use J Store" [sic], "thesis binding" 45

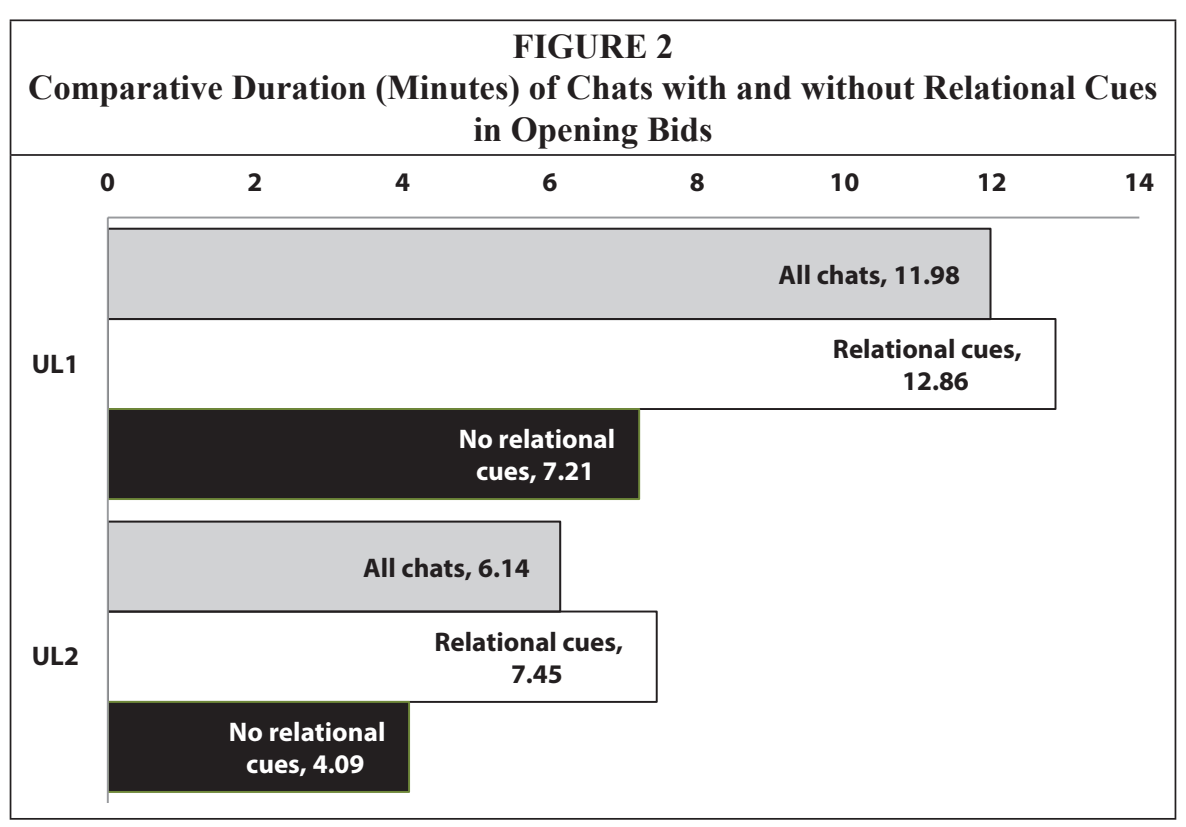


3. "Retail" bids: "do you have" a specific item or "are there any" items that fit my need

The librarian's response to a summons may be a simple greeting, which opens a state of talk but allows the student to shape the interaction. Or the librarian can direct the talk to a particular purpose aligned with professional identity (for example: "Do you have a reference question?"). The librarian's response to a search engine bid may lean toward service by providing links to the resource or information needed with no greeting. Alternatively, the librarian may lean toward teaching by engaging in conversation about the underlying research need. In response to a retail bid - "is there a book on Rosie the Rivter [sic]?" - the librarian can provide links to catalog records that fit the need or instead choose to greet the student, express interest in the topic, or inquire about the scope of the assignment.

To illustrate how recognition operates in opening exchanges, see transcripts 1 and 2. Both student opening bids lack relational cues: "do you hear that bird sound?" "Is the third floor of the library a quite [sic] zone?" And both impose a stereotypical librarian identity as someone responsible for maintaining silence. Both librarians greet the student, leading to an open state of talk. In transcript 1, recognition is delayed because the student assumes incorrectly that the librarian is located nearby and can hear the disturbance. Once the confusion is resolved, the librarian responds to the complaint as a request for service, implicitly accepting the identity of "shusher" on her/his own behalf as well as that of a colleague at the student's location.

The librarian in transcript 2 deflects the identity offered. Rather than responding to the implied complaint as a bid for service, she/he reframes the question factually, providing information but leaving it up to the student to find a quiet place to study.

\section{TRANSCRIPT 1}

UL1 3104462

19:41 [Student] do you hear that bird sound?

19:41 [Librarian] hello

19:41 [Student] do you hear it?

19:42 [Librarian] I'm in [campus] library

19:42 [Student] I'm on the second floor and there is an obnoxious chirping

19:42 [Librarian] I'll call over to the desk and report

19:42 [Student] thank you

19:44 [Librarian] a librarian is coming to look...

19:44 [Student] thank you :)

$19: 44$ [Student] this is so cool

19:44 [Student] i love IM a librarian

19:45 [Student] have a great day!!

\section{TRANSCRIPT 2}

\section{UL2 12.162822}

11:28 [Student] Is the third floor of the library a quite zone?

11:28 [Librarian] hello

$11: 28$ [Librarian] the third floor is fairly quiet.

11:29 [Librarian] there are study carrels on the 3rd floor. the lower level is also quiet.

11:30 [Student] Thank you I just wasn't sure. Heard lots of chatter on the third floor so wasn't sure

11:30 [Librarian] what area of the third floor/

11:31 [Librarian]? 
The student returns with an observation about "lots of chatter," prompting the librarian to ask for more detail, but the student leaves the chat. The student returns 30 minutes later with another complaint (transcript not included). CA theory indicates that if the student were actually asking a question, information would be a preferred response. The renewed complaint shows the question was an implied bid for service. UL2 librarians staffed live chat from a service desk, so it might not be possible for them to intervene in person, even if they had wanted to.

In transcript 3, the student opens with a bid for a specific item. The librarian makes a preferred response: offering to look for the item. However, the librarian conveys warmth by greeting the student and by saying "I'd be happy to," which prompts the student to recognize that this is not an automated response. The question "Are you a computer?" suggests that the student lacks social cues to frame the encounter as a conversation with a professional rather than a retail transaction. After confirming that the librarian is not a computer, the next guess about identity is that of a student assistant. The student's delight about interacting with a librarian ("nice!!") is endearing.

\section{TRANSCRIPT 3}

\section{UL1 3092857}

14:56 [Student] do you have big fish the movie?

14:56 [Librarian] Hi

14:56 [Student] hey

14:56 [Librarian] I'd be happy to check on that

$14: 56$ [Student] ok cool

$14: 56$ [Student] are you a computer?

14:57 [Librarian] No-I'm a real person :)

14:57 [Student] are you a student?

14:57 [Librarian] No-I'm a librarian

14:57 [Librarian] Are you looking for the Tim Burton movie?

14:57 [Student] nice!!

The opening bid in transcript 4 is an implied complaint about circulation policy. Here the librarian responds with a greeting to start a conversation. The next move is to answer the question. However, the librarian does not consider the transaction complete after providing information. An option for meeting the underlying need (using a scanning service) quickly follows. The conversation shifts (marked by the student's "oh") into a bid for instruction: "how do I do that?" The librarian's next two moves save face for the student. ${ }^{46}$ First, asking "have you used that" makes it acceptable for the student not to know the procedure. Second, offering to "walk you through" makes

\section{TRANSCRIPT 4 \\ UL1 3089270}

16:12 [Student] Why am I not allowed to request a periodical from the law stacks?

16:12 [Librarian] Hello

16:12 [Librarian] periodicals cannot be checkout out, they stay in the library

16:12 [Librarian] but you can request a scan of an article that you need

16:12 [Student] oh, how do I do that?

16:13 [Librarian] using ILLiad, our inter-library loan system

16:13 [Librarian] have you used that, or I can walk you through?

16:13 [Student] i have used it, but could use some help 
it easier for the student to request help. Note that librarian offers to accompany and coach the student, teaching a practical skill that will be useful in the future, rather than to complete the request for the student.

Transcript 5 is another example of reframing an opening bid to balance service and teacher identity. The student's use of "we" is an identity move associating him/herself with the library or the university. The use of "rent" (rather than "borrow" or "check

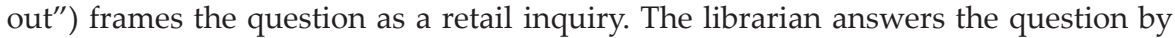
deftly modeling library vocabulary without condescending. The respect and attention to learning demonstrated in this response opens the door to an instruction bid, which the student softens with "just curious" to save face, downplaying the importance of the request. The student responds to the basic instruction with enthusiastic gratitude.

\section{TRANSCRIPT 5 \\ UL2 12.021220}

21:12 [Student] do we have movies to watch for a rent?

$21: 13$ [Librarian] yes, the library has a dvd collection. is there a particular title you are searching for?

21:13 [Student] i was just curious, where can i look them up?

$21: 13$ [Librarian] you can search the library catalog (click on the tab that says 'books $\&$ more') here: [URL, library home page]

21:14 [Student] sweet! Thank you very much!

Some concepts and skills are too complex to address in live chat. For others, reframing transactional opening bids is not only possible but desirable. The conversational moves to assert a teacher identity are "dispreferred" in the structural sense of CA theory; but, in these data sets, longer chats correlate with expressions of student satisfaction coded at "Awesome," such as "awesome," "sweet," or "librarians rock!" (see figure 3). At UL1, "Awesome" chats were 41 percent longer than chats without such markers; at UL2,

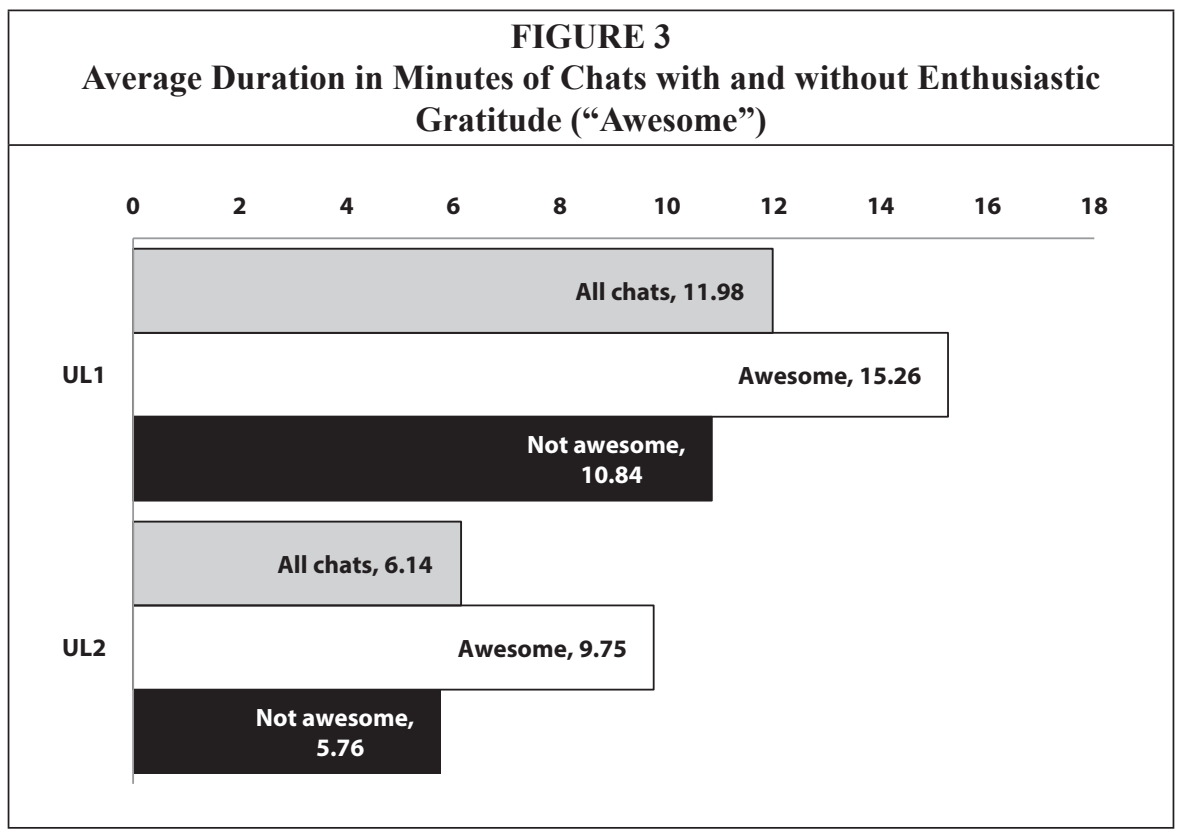


they were 69 percent longer. The finding that structurally "dispreferred" responses may lead to welcome outcomes supports and extends CA theory.

\section{Limitations and Future Research}

The data do not indicate whether the "librarian" is a student assistant or a professional, but professional librarians train and supervise student assistants, and CA theory applies equally to them. Further research is needed to learn whether student assistants bring particular strengths and weaknesses to live chat in comparison to professional librarians. Another limitation to this study is the omission of attention to explicit teaching strategies due to length constraints. Valuable research can be done on how librarians avoid teaching or include it, such as sending direct links to resources rather than coaching patrons on how to find them. Another fruitful direction is to investigate what percentage of libraries restrict chat to brief questions. Interviews with administrators and reference staff in libraries that do and do not restrict the service would contribute to understanding the reasons for the varied philosophy and its impact on student learning, especially in institutions with large numbers of commuters and distance learners.

\section{Discussion and Conclusions}

This study found that sets of chat transcripts from two libraries vary along several variables. Opening exchanges differed substantially in the use of relational cues (greetings, introductions, words of courtesy, and verbal "softeners"). Slicing the data into sets of transcripts that students opened with relational cues and without them, students' use of relational cues correlated with far longer chats. And comparing longer chats with briefer chats, longer interactions included more expressions of enthusiastic gratitude. In addition to these quantitative findings, the study provided qualitative evidence of the strategies librarians use to assert a teacher identity, even in the most basic exchanges.

Librarians create a professional identity in their own eyes as well as in students' understanding through their everyday responses to chat reference questions. The tension between the librarians' service and teacher identities is played out empirically in these data. The librarian's service identity comes into play when information is offered without engaging the student's topic or process. Direct service maximizes efficiency and frequently prompts enthusiastic gratitude, but it also might give students the impression that the librarian's role is to provide relevant articles rather than to teach research skills. Because students are unfamiliar with what librarians can do for them, ${ }^{47}$ it is up to the librarian to shape the roles appropriate to the talk.

Librarians assert their teacher identity when they reframe such transactions as conversations to promote student growth and discovery. Identity moves can be verbal ("Do you have a reference question?") but are more often a structural feature of the conversation. One contribution of CA theory to professional practice is the understanding that omitting relational cues is not necessarily rudeness on the student's part. It is a familiar technique used for a request when there is no prior relationship (asking a stranger the time) or when the appropriate role is unclear: customer or learner.

Therefore, practitioners should reflect on how their first responses define the service for students who enter the chat uncertain about expected roles. To foster engaged learning, librarians need to be aware of and overcome the prevailing tendency to provide a "preferred" response in terms of CA theory. As figure 3 shows, "dispreferred" responses reframing transactional questions into learning opportunities tend to generate longer interactions with more evidence of enthusiastic gratitude from students.

This study's findings make several important, if incremental, contributions to the scholarly and professional literature. For the scholarly community of LIS researchers, the main contribution is demonstrating the value of investigating professional iden- 
tity unfolding in real time, and not only in the abstract. For researchers interested in applying CA to other areas of investigation, the study delineates how conversational moves reveal meaning by examining how the response ratifies or rejects the previous move. For practicing academic librarians, the main contribution is in highlighting the conversational strategies that can make the rapid-fire work of live chat richer and more engaging for both the librarian and the student.

For library administrators, the significance is to understand the impact of staffing decisions and specifically how much focus and attention is needed to make VR a classroom as well as a service counter. Having librarians monitor chat reference at a busy service desk is cost-effective but can impede a real and significant educational role. As the ACRL Standards for Libraries in Higher Education stipulate, extending education into a variety of contexts is especially important for institutions with large numbers of commuters and distance learners.

\section{Acknowledgments}

An early stage of analysis was presented as a poster at the Library Assessment Conference 2014, Seattle, Washington. I am grateful to Deb Blecic, Tina Griffin, Kara Malenfant, Pam Sessoms, Mihail Tsvetkov, Steve Wiberley, Anna Wolf, Simon Zuberek, and colleagues at both institutions whose work in these transcripts makes me proud to share their profession.

\section{Notes}

1. "Standards for Libraries in Higher Education I Association of College \& Research Libraries (ACRL)," available online at www.ala.org/acrl/standards/standardslibraries [accessed 6 December 2014].

2. Paula R. Dempsey, "Interactive Service and Professional Culture: Academic Reference Librarians in an Emerging Context," in Advances in Library Administration and Organization, vol. 24, 2008, 91-116, available online at www.emeraldinsight.com/books.htm?chapterid=1760077 [accessed 18 May 2016].

3. Pauline Wilson, "Librarians as Teachers: The Study of an Organization Fiction," Library Quarterly 49, no. 2 (Apr. 1979): 146-62.

4. Constance Miller and James Rettig, "Reference Obsolescence," RQ 25, no. 1 (1985): 52-58.

5. James K. Elmborg, "Teaching at the Desk: Toward a Reference Pedagogy," portal: Libraries and the Academy 2, no. 3 (2002): 455-64, doi:10.1353/pla.2002.0050.

6. Scott Walter, "Librarians as Teachers: A Qualitative Inquiry into Professional Identity," College \& Research Libraries 69, no. 1 (Jan. 2008): 51-71.

7. Miriam L. Matteson, Jennifer Salamon, and Lindy Brewster, "A Systematic Review of Research on Live Chat Service," Reference \& User Services Quarterly 51, no. 2 (Dec. 1, 2011): 181, doi:10.5860/rusq.51n2.172.

8. Christina M. Desai and Stephanie J. Graves, “Instruction via Instant Messaging Reference: What's Happening?" Electronic Library 24, no. 2 (Mar. 1, 2006): 185, doi:10.1108/02640470610660369.

9. Ibid., 187.

10. Susan Avery and David Ward, "Reference Is My Classroom: Setting Instructional Goals for Academic Library Reference Services," Internet Reference Services Quarterly 15, no. 1 (2010): 35-51.

11. Marie L. Radford et al., “On Virtual Face-Work: An Ethnography of Communication Approach to a Live Chat Reference Interaction," Library Quarterly 81, no. 4 (Oct. 2011): 441.

12. Terrence W. Epperson and Alan Zemel, "Reports, Requests, and Recipient Design: The Management of Patron Queries in Online Reference Chats," Journal of the American Society for Information Science and Technology 59, no. 14 (Dec.1, 2008): 2279, doi:10.1002/asi.20930.

13. Epperson and Zemel, "Reports, Requests, and Recipient Design."

14. Yannis Pappas and Clive Seale, "The Opening Phase of Telemedicine Consultations: An Analysis of Interaction," Social Science \& Medicine 68, no. 7 (2009): 1229-37, doi:http://dx.doi. org/10.1016/j.socscimed.2009.01.011.

15. Marilyn R. Whalen and Don H. Zimmerman, "Describing Trouble: Practical Epistemology in Citizen Calls to the Police," Language in Society 19, no. 4 (Dec. 1, 1990): 465-92. 


\section{Opening Exchanges in Virtual Reference Shape the Potential for Teaching 467}

16. Susan Danby, Carolyn Baker, and Michael Emmison, "Four Observations on Openings in Calls to Kids Help Line," in Calling for Help: Language and Social Interaction in Telephone Helplines (Philadelphia: John Benjamins, 2005), 133-51, available online at http://site.ebrary.com/lib/uic/ reader.action?ppg=151\&docID $=10090671 \& \mathrm{tm}=1463592350999$ [accessed 18 May 2016].

17. Anssi Peräkylä and Sanna Vehvilfinen, "Conversation Analysis and the Professional Stocks of Interactional Knowledge," Discourse E Society 14, no. 6 (Nov. 1, 2003): 727-50, doi:10.1177/09579265030146003.

18. John Budd, "Discourse Analysis and the Study of Communication in LIS," Library Trends 55, no. 1 (2006): 65-82.

19. Michael Moerman, Talking Culture: Ethnography and Conversation Analysis (Philadelphia: University of Pennsylvania Press, 1988). $3-16$.

20. Deborah Schiffrin, "Conversation Analysis," Annual Review of Applied Linguistics 11 (1990):

21. Budd, "Discourse Analysis and the Study of Communication in LIS," 69.

22. Christian M.I.M. Matthiessen and Diana Slade, "Analysing Conversation," in The SAGE Handbook of Sociolinguistics (London: SAGE, 2011), 375-95, available online at http://knowledge. sagepub.com/view/hdbk_sociolinguistics/n27.xml [accessed 18 May 2016].

23. Angela Cora Garcia and Jennifer Baker Jacobs, "The Eyes of the Beholder: Understanding the Turn-Taking System in Quasi-Synchronous Computer-Mediated Communication," Research on Language \& Social Interaction 32, no. 4 (1999): 337-67, doi:10.1207/S15327973rls3204_2; Budd, "Discourse Analysis and the Study of Communication in LIS," 71.

24. Epperson and Zemel, "Reports, Requests, and Recipient Design," 2268.

25. Epperson and Zemel, "Reports, Requests, and Recipient Design."

26. Matthiessen and Slade, "Analysing Conversation," 389.

27. Epperson and Zemel, "Reports, Requests, and Recipient Design," 2273.

28. Don H. Zimmerman, "Identity, Context and Interaction," in Identities in Talk, eds. Charles Antaki and Sue Widdicombe (Thousand Oaks, Calif.: SAGE, 1998), 98.

29. Emanuel A. Schegloff, "Sequencing in Conversational Openings," American Anthropologist, New Series, 70, no. 6 (1968): 1092.

30. Emanuel A. Schegloff, "Identification and Recognition in Telephone Conversation Openings," in Everyday Language: Studies in Ethnomethodology, ed. George Psathas (New York: Irvington Publishers, distributed by Halsted Press, 1979), 23-78; Epperson and Zemel, "Reports, Requests, and Recipient Design."

31. Harvey Sacks, "Chapter 15: Part VIII, Spring 1972," in Lectures on Conversation, vol. II, 2 vols. (Hoboken, N.J.: Wiley-Blackwell, 1992), 519-75, available online at http://onlinelibrary.wiley. com/doi/10.1002/9781444328301.ch15/summary [accessed 18 May 2016].

32. Erving Goffman, "Replies and Responses," Language in Society 5, no. 3 (Dec. 1, 1976): 257-313.

33. Kimberly K. Vardeman and Ian Barba, "Reference in 160 Characters or Less: The Role of

Text Messaging in Virtual Reference Services," Internet Reference Services Quarterly 19, no. 3/4 (Oct.2, 2014): 163-79, doi:10.1080/10875301.2014.984098.

34. Reference and User Services Association, "Measuring and Assessing Reference Services and Resources: A Guide," American Library Association, n.d., available online at http://www.ala. org/rusa/sections/rss/rsssection/rsscomm/evaluationofref/measrefguide [accessed 18 May 2016].

35. S.J. Tracy, “Qualitative Quality: Eight 'Big-Tent' Criteria for Excellent Qualitative Research," Qualitative Inquiry 16, no. 10 (Dec. 1, 2010): 847, doi:10.1177/1077800410383121.

36. Ibid.

37. Ken W. Parry, "Constant Comparison," in Encyclopedia of Social Science Research Methods (Thousand Oaks, Calif.: SAGE, 2004), 181-82.

38. If students inadvertently left the chat window and returned to a new window assuming (rightly or wrongly) that they were chatting with the same librarian, the duration included the second transcript.

39. Sarah Passonneau and Dan Coffey, "The Role of Synchronous Virtual Reference in Teaching and Learning: A Grounded Theory Analysis of Instant Messaging Transcripts," College \& Research Libraries 72, no. 3 (May 2011): 276-94.

40. Pnina Shachaf and Sarah M. Horowitz, "Virtual Reference Service Evaluation: Adherence to RUSA Behavioral Guidelines and IFLA Digital Reference Guidelines," Library \& Information Science Research 30, no. 2 (June 2008): 122-37, doi:10.1016/j.lisr.2007.12.002.

41. Douglas Ezzy, Qualitative Analysis: Practice and Innovation (Routledge, 2002), 28.

42. Ibid., 10 .

43. Ian V. Cornelius, Meaning and Method in Information Studies (Norwood, N.J.: Ablex, 1996).

44. Sharon Lauricella and Robin Kay, "Exploring the Use of Text and Instant Messaging in Higher Education Classrooms," Research in Learning Technology 21 (Sept. 3, 2013), doi:10.3402/rlt. v21i0.19061. 
45. Search engine bids might increase as libraries develop reference knowledge bases to answer common questions through FAQs rather than direct interaction.

46. Tammi M. Owens, "Communication, Face Saving, and Anxiety at an Academic Library's Virtual Reference Service," Internet Reference Services Quarterly 18, no. 2 (2013): 139-68, doi:10.10 80/10875301.2013.809043; Radford et al., "On Virtual Face-Work."

47. E. Pickard and F. Logan, "The Research Process and the Library: First-Generation College Seniors vs. Freshmen," College E Research Libraries 74, no. 4 (July 1, 2013): 399-415, doi:10.5860/ crl-348. 